\title{
Religiosity for HIV prevention in Uganda: a case study among Muslim youth in Wakiso district
}

*Kagimu M ${ }^{1,2,3}$, Guwatudde D ${ }^{2}$, Rwabukwali C ${ }^{4}$, Kaye S ${ }^{1,5}$, Walakira Y ${ }^{1}$, Ainomugisha D ${ }^{1}$

1. Islamic Medical Association of Uganda

2. Makerere University School of Public Health

3. Department of Medicine, Makerere University College of Health Sciences.

4. Department of Sociology, Makerere University

5. Makerere University School of Public Health - CDC/HIV/AIDS Fellowship Program

\begin{abstract}
Background: Evidence for the association between religiosity and HIV infections is limited. Sujda, the hyper-pigmented spot on the forehead due to repeated prostration during prayers and fasting to worship, involving abstaining from food, drink and sex during daytime in Ramadhan and other specified days, are measures of religiosity among Muslims

Objectives: To assess the association between religiosity and HIV infections.

Methods: This was an unmatched case-control study with 29 HIV positive cases and 116 HIV negative controls, from 1224 Muslims, 15-24 years.

Results: Respondents without Sujda had more HIV infections (odds ratio 2.90, 95\% CI 1.07-7.86, p=0.029). Those with Sujda were more likely to abstain from sex (odds ratio 1.69, 95\% CI 1.31-2.20, p<0.001) and be faithful in marriage (odds ratio 1.69, 95\% CI 1.11-2.57, $\mathrm{p}=0.012$ ). Respondents without Sujda were more likely to have ever taken alcohol before sex (odds ratio 5.00, 95\% CI 1.39-17.95, $\mathrm{p}=0.006$ ) and to have ever used narcotics (odds ratio 2.12, 95\% CI, 1.11-4.05, $\mathrm{p}=0.019$ ). Respondents who fasted less, had more HIV infections (odds ratio 2.46, 95\% CI 1.07-5.67, $\mathrm{p}=0.028$ ).

Conclusion: Sujda and fasting were associated with lower HIV infections. Imams should use this information to intensify the Islamic approach to HIV prevention.

Key words: Religiosity, HIV Prevention, Uganda, Muslim.

African Health Sciences 2012; 12(3): 282 - 290 http://dx.doi.org/10.4314/ahs.v12i3.6
\end{abstract}

\section{Introduction}

According to the HIV/AIDS sero-behavioral survey of 2004-2005, the HIV prevalence among Ugandan Muslim communities was $5.0 \%$. Although this prevalence is lower than other religious denominations (Protestants 7.1\%, Catholics 6.3\%), it is still quite high ${ }^{1}$. New infections continue to occur in Muslim communities. It is thought that a high level of religiosity, where Muslims are committed to practicing the teachings of their religious belief system, is likely to lead to lower HIV infection rates ${ }^{2,3,4}$. Indeed organizations like the Islamic Medical

*Correspondence author:
Magid Kagimu
Associate Professor
Department of Medicine
Makerere University College of Health Sciences and
Chairman Islamic Medical Association of Uganda
P. O. Box 2773
Kampala, Uganda
Telephone: 256-782-016868
Email: mmkagimu@,utlonline.co.ug or
imau@,utlonline.co.ug

Association of Uganda (IMAU) have been implementing interventions using the Islamic approach to HIV/AIDS. This approach has the following five pillars: ${ }^{5}$

1. Believing in Allah and Prophet Muhammad (Peace be upon him).

2. Acquiring scientific knowledge about HIV/ AIDS

3. Making use of relevant Islamic teachings and practices

4. Forming partnerships with and making use of religious leaders and their administrative structures.

5. Making use of the concept of Jihad Nafs (selfcontrol - the struggle of the soul against temptations), by each individual to combat AIDS.

Individuals, families and communities are being encouraged by trained Imams to use this five-pillar approach in their fight against HIV/AIDS. This is what is called the Jihad on AIDS. 
However, there is limited data on the association between religiosity and HIV infections among Muslim communities. It is not clear whether those committed to following Islamic teachings and practices have lower HIV infection rates.

The study was done to assess the association between religiosity and HIV infections among Muslim communities. One of the markers of religiosity for Muslims, which is easily observable, is Sujda. This is a hyper-pigmented mark on the forehead which comes as a result of prostration during regular prayers. Muslims are encouraged to pray five times a day as one of the five pillars of Islam. Sujda was the main objective parameter of religiosity which was measured in the study. Another practice among Muslims is fasting. This is also a measure of religiosity which can be assessed through self-reporting by respondents. It is also one of the five pillars of Islam. It is prescribed during the month of Ramadhan and during some other specified days as an act of worship to Allah. When fasting, Muslims abstain from food, drink and sex during daytime.

\section{Methods}

\section{Study setting}

The Islamic Medical Association of Uganda, a faithbased non-governmental organization consisting of Muslim health professionals, runs a hospital called Saidina Abubakar Islamic Hospital (SAIH). This hospital which was opened in 2005 is located at Wattuba, $14 \mathrm{Km}$ from Kampala city, on Bombo road in Wakiso district. IMAU hospital staff have been working with Imams close to the hospital to educate the surrounding communities about issues of HIV prevention and control using the five-pillar Islamic Approach to HIV/AIDS. The Imams and their assistants were trained to use a curriculum with both scientific information and Islamic teachings, in the process of educating their communities ${ }^{5}$. This curriculum was developed by IMAU health professionals in conjunction with experienced religious leaders. IMAU facilitators then trained trainers in the use of this curriculum. These trainers included health professionals and teachers within the target communities. The trainers then trained the Imams and their assistants, using the curriculum, during 5-day workshops of around 30 participants. Each Imam in conjunction with his mosque community identified volunteers to assist him and to participate in the training. These volunteers, who were called community educators, included one male youth, one female youth, one adult female, and one adult male. After the training, the Imam and his assistants educated their communities on issues of HIV prevention using the curriculum. The education occurred during sermons for Friday Juma prayers, during home visits and during group discussions usually after the prayers. The community educators also referred clients to health facilities for services such as HIV counseling and testing, prevention of mother to child HIV transmission services, and antiretroviral therapy services. They monitored their activities by recording them on forms provided to them by IMAU trainers. The trainers continued to provide support supervision and on-job training to the community educators during monthly meetings, field visits, and refresher training workshops.

IMAU used a similar faith-based approach to educate Christian communities about issues of HIV prevention and control. Indeed the training workshops conducted by IMAU trainers included both Muslim and Christian community educators. The scientific information on HIV/AIDS was the same for both communities. The supportive faith teachings differed in some ways and each community was made to focus on their own faith teachings. However, they found that on many issues the faith teachings were similar. As a result both communities realized that the combined workshops had enriched their understanding of religiosity. After the training, community educators from each faith went on to educate their own communities using similar methods of sermons, group talks and home visits.

A convenience sample of Muslim and Christian communities from 30 mosques and 30 churches around the hospital was selected to participate in the study. The study research assistants were nurses and counselors from Saidina Abubakar Islamic Hospital. They were trained on how to collect the required data. They were introduced to the respondents' homes by the community educators. Because of different faith traditions, it was planned that the analysis of data for Christians and Muslims was to be done separately.

\section{Study design}

The study design was an unmatched case-control study. The sample size for Muslims was calculated to be 100 cases and 400 controls using a formula for unmatched case control studies with multiple controls $^{6}$. A similar sample size was calculated for Christians. 


\section{Selecting cases and controls}

Cases were defined as respondents between 15-24 years who tested positive for HIV. Controls were defined as respondents who tested HIV negative in the same age group. They were selected randomly from HIV negative respondents at the completion of the study. The respondents were identified through home-based HIV counseling and testing which was done by IMAU hospital staff for communities surrounding the places of worship but specifically targeting homes with $15-24$ year old clients.

\section{Measurements HIV testing}

HIV testing was done using rapid test kits following the standard protocol from the Uganda Ministry of Health ${ }^{7}$. The blood was first tested using Determine HIV-1/2 (Abbot, Tokyo, Japan) rapid test kit. For an HIV negative result, no further test was done. For an HIV positive result another test was done using the HIV-1/2 STAT-PAK (Chembio, Medford, NY) test kit. If this test result was positive, the client was recorded as positive. If the result was negative, a third test was done as a tie breaker using UniGold Recombigen HIV test (Trinity Biotech, Wicklow, Ireland). If this gave a positive result, the client was recorded as HIV positive, and if it was negative, the client was recorded as HIV negative.

\section{Religiosity, socio-demographic characteristics and HIV-risk behaviors}

Religiosity was measured using a modified instrument called the Multidimensional Measure of Religiousness / Spirituality for Use in Health research ${ }^{8}$. Relevant questions were selected from this instrument. Other questions thought to be important for the target communities were added. These included asking about Sujda and observing its presence on the face, for the Muslim respondents. Questions on socio-demographic characteristics and HIV-risk behaviors and practices were also added. The instrument was tested on 359 clients and it was found to have adequate validity and reliability in assessing religiosity.

\section{Statistical analysis}

Double data entry was done in EpiData statistical package version $2.1 \mathrm{~b}$. The data was cleaned and the final data set made. The statistical analysis was done in STATA version 10.0 computer program?. The information was organized to produce categorical frequency data. The Chi-squared test was used to assess the association between any two groups and the $\mathrm{p}$-value $<0.05$ was regarded as significant. ${ }^{10}$

\section{Ethical considerations}

The study was approved by Makerere University School of Public Health Institutional Review Board and the Uganda National Council of Science and Technology.

\section{Results}

\section{Significant factors associated with HIV infections}

From July to December 2010 a total of 4268 clients between 15 and 24 years were tested for HIV, of which 1224 were Muslims. There were 29 HIV positive Muslims, giving a prevalence rate of $2.4 \%$. The prevalence rate for Christians was 3.6\%.

It was initially thought that within the study period the required sample size of 100 Muslim HIV positive and 100 Christian HIV positive respondents would be obtained. The required sample size was achieved for Christians but not for Muslims because of the lower HIV prevalence rates for the latter. It was not possible to continue with the study in order to get the required sample size for the Muslims due to limited resources. This means the power of the study to detect significant differences between cases and controls was diminished. However, any statistically significant differences observed in the analysis of the smaller sample size, were considered to be important because they could be detected even with this lower power of the study. In the process of identifying cases of HIV infection, the information gathered from the respondents tested for HIV provided cross-sectional data for these communities. This data was analyzed to provide additional insight into the variables of interest. The strength of evidence from this cross-sectional data is recognized to be lower than that of the casecontrol study. ${ }^{11}$ However, the information obtained was considered to be important in supporting the findings of the case-control study and providing possible mechanisms for the results.

One hundred and sixteen HIV negative Muslim controls were randomly selected for the 29 HIV positive Muslim cases. The statistically significant differences between cases and controls are shown in table 1. Respondents with high HIV risk perception who thought they were likely to be infected were significantly more likely to test HIV positive (odds ratio 9.57, 95\% CI 2.07-44.26, 
$\mathrm{p}<0.001)$. Respondents with a lower level of religiosity as measured by absence of Sujda were more likely to test HIV positive (odds ratio 2.90, 95\% CI 1.07-7.86, $\mathrm{p}=0.029)$. Respondents who had lost one or both parents were also more likely to be HIV positive (odds ratio 4.51, 95\% CI 1.78- 11.40, $\mathrm{p}<0.001)$.

Table 1: Comparison of factors significantly associated with HIV infections among Muslim cases and controls

\begin{tabular}{lccccc}
\hline $\begin{array}{l}\text { Factors } \\
\text { Risk Perception: }\end{array}$ & Cases n (\%) & Controls n (\%) & Odds ratio & 95\% CI & p-value \\
$\begin{array}{l}\text { Chances one might have HIV: } \\
\text { Low: not likely }\end{array}$ & $23(17)$ & $110(83)$ & & & \\
$\begin{array}{l}\text { High: likely } \\
\text { Sujda: }\end{array}$ & $6(67)$ & $3(33)$ & 9.57 & $2.07-44.26$ & $<0.001$ \\
$\begin{array}{l}\text { Have Sujda } \\
\text { Yes }\end{array}$ & $6(11)$ & $49(89)$ & & & \\
$\begin{array}{l}\text { No } \\
\text { Parental existence }\end{array}$ & $22(26)$ & $62(74)$ & 2.90 & $1.07-7.86$ & 0.029 \\
$\begin{array}{l}\text { Both parents alive } \\
\text { One or both parents } \\
\text { parents died }\end{array}$ & $9(10)$ & $79(90)$ & & & \\
\hline
\end{tabular}

The factors associated with HIV infection in crosssectional data among all Muslim respondents are shown in table 2. Respondents with high risk perception of HIV infection, those who had lost one or both parents, and those who did not have Sujda were significantly associated with higher HIV infection rates as found in the case-control study. Additional factors significantly associated with HIV infection in cross-sectional data analysis among all Muslim respondents included fasting for less than one month in a year, ever having sex during menstruation and ever drinking alcohol.

Table 2: Comparison of factors associated with HIV among all Muslim respondents

\begin{tabular}{|c|c|c|c|c|c|}
\hline Factors & $\begin{array}{l}\text { HIV } \\
\text { Positive } \\
\text { n (\%) }\end{array}$ & $\begin{array}{l}\text { HIV } \\
\text { Negative } \\
\text { n (\%) }\end{array}$ & Odds ratio & $95 \% \mathrm{CI}$ & p-value \\
\hline \multicolumn{6}{|l|}{ Religiosity } \\
\hline \multicolumn{6}{|l|}{ Have Sujda } \\
\hline Yes & $6(1)$ & $487(99)$ & & & \\
\hline No & $22(3)$ & $651(97)$ & 2.74 & $1.10-6.83$ & 0.024 \\
\hline \multicolumn{6}{|l|}{ Fasting } \\
\hline High ( $\geq 1$ month per year) & $21(2)$ & $1,009(98)$ & & & \\
\hline $\begin{array}{l}\text { Moderate }(<1 \text { month per } \\
\text { year) }\end{array}$ & $8(5)$ & 156(95) & 2.46 & $1.07-5.67$ & 0.028 \\
\hline \multicolumn{6}{|l|}{ Parental existence } \\
\hline Both parents alive & $9(1)$ & $720(99)$ & & & \\
\hline One or both died & $19(4)$ & $470(94)$ & 3.23 & $1.45-7.23$ & 0.003 \\
\hline \multicolumn{6}{|l|}{ Behavioral factors } \\
\hline \multicolumn{6}{|l|}{$\begin{array}{l}\text { Ever had sex during } \\
\text { menstruation }\end{array}$} \\
\hline No & $15(2)$ & 678(98) & & & \\
\hline Yes & $7(5)$ & $123(95)$ & 2.57 & $1.02-6.46$ & 0.037 \\
\hline \multicolumn{6}{|l|}{ Ever drank alcohol } \\
\hline No & $20(2)$ & $980(98)$ & & & \\
\hline Yes & $9(4)$ & $193(96)$ & 2.28 & $1.02-5.10$ & 0.038 \\
\hline \multicolumn{6}{|l|}{ Risk perception } \\
\hline \multicolumn{6}{|l|}{ Chances of having HIV } \\
\hline Low & $23(2)$ & $1,110(98)$ & & & \\
\hline High(Very likely) & $6(9)$ & $60(91)$ & 4.83 & $1.88-12.37$ & $<0.001$ \\
\hline
\end{tabular}


Respondents who fasted for less than one month per year had a higher HIV infection rate compared to those who fasted more often (odds ratio 2.46, 95\% CI 1.07-5.67, $\mathrm{p}=0.028)$. Those who ever had sex during menstruation were more likely to have HIV infections (odds ratio 2.57, 95\% CI 1.02-6.46, $\mathrm{p}=0.037$ ). Respondents who had ever taken alcohol in their life also had higher HIV infection rates (odds ratio $2.28,95 \%$ CI $1.02-5.10, \mathrm{p}=0.037$ )

\section{Sujda and HIV-risk behaviors}

The association between Sujda indicative of high religiosity and HIV-risk behaviors is shown in table

3. Respondents with Sujda were more likely to abstain from sex (odds ratio 1.69, 95\% CI 1.31$2.20, \mathrm{p}<0.001)$. Respondents with Sujda were also more likely to be faithful in marriage (odds ratio 1.69, 95\% CI 1.1-2.57, $\mathrm{p}=0.012$ ). Respondents with no Sujda were more likely to have ever drank alcohol (odds ratio $2.08,95 \%$ CI $0.99-4.38, \mathrm{p}=0.049$ ), to have ever been drunk (odds ratio 2.08, 95\% CI 0.99 $4.38, \mathrm{p}=0.049$ ), to be drinking nowadays (odds ratio 2.80, 95\% CI 1.01-7.76, $\mathrm{p}=0.039)$ and to have ever taken alcohol before sex (odds ratio 5.00, 95\% CI 1.39-17.95, $\mathrm{p}=0.006)$. Respondents with no Sujda were also more likely to have ever used narcotic drugs for recreation (odds ratio 2.12, 95\% CI 1.11-4.05, $\mathrm{p}=0.019)$.

Table 3: Association between Sujda and HIV-risk behaviors among all Muslim respondents

\begin{tabular}{|c|c|c|c|c|c|}
\hline Factors & \multicolumn{2}{|c|}{ Sujda n $(\%)$} & $\begin{array}{l}\text { Odds ratio } \\
\text { Sujdan (\%) }\end{array}$ & $95 \% \mathrm{CI}$ & p-value \\
\hline \multicolumn{6}{|l|}{ Ever had sex: } \\
\hline Yes & $320(66)$ & $513(76)$ & & & \\
\hline No (Abstaining) & $167(34)$ & $158(24)$ & 1.69 & $1.31-2.20$ & $<0.001$ \\
\hline \multicolumn{6}{|c|}{ Sex outside marriage in last 12 months } \\
\hline Yes & $57(40)$ & $139(53)$ & & & \\
\hline No (Being faithful) & $86(60)$ & $124(47)$ & 1.69 & $1.11-2.57$ & 0.012 \\
\hline \multicolumn{6}{|l|}{ Ever drank alcohol } \\
\hline Yes & $35(7)$ & $150(22)$ & & & \\
\hline No & $446(93)$ & $517(88)$ & 2.08 & $0.99-4.38$ & 0.049 \\
\hline \multicolumn{6}{|l|}{ Ever been drunk } \\
\hline Yes & $15(41)$ & $85(59)$ & & & \\
\hline No & $22(59)$ & $60(41)$ & 2.08 & $0.99-4.38$ & 0.049 \\
\hline \multicolumn{6}{|l|}{ Drink nowadays } \\
\hline Yes & $5(13)$ & $42(29)$ & & & \\
\hline No & $34(87)$ & $102(71)$ & 2.80 & $1.01-7.76$ & 0.039 \\
\hline \multicolumn{6}{|c|}{ Ever taken alcohol before sex } \\
\hline Yes & $3(9)$ & $44(34)$ & & & \\
\hline No & $29(91)$ & $85(66)$ & 5.00 & $1.39-17.95$ & 0.006 \\
\hline \multicolumn{6}{|c|}{ Ever used narcotic drugs } \\
\hline Yes & $13(3)$ & $37(6)$ & & & \\
\hline No & 468(97) & $627(94)$ & 2.12 & $1.11-4.05$ & 0.019 \\
\hline
\end{tabular}

\section{Fasting and HIV-risk behaviors}

The association between fasting and HIV-risk behaviors and practices is shown in table 4. Respondents who fasted for less than one month per year were more likely not to be circumcised (odds ratio 6.92, 95\% CI 2.09-22.94, $\mathrm{p}<0.001$ ), and also more likely to have ever had sex during menstruation (odds ratio 1.92, 95\% CI 1.21-3.06, $\mathrm{p}=0.005$ ). 
Table 4: Association between fasting and HIV-risk behaviors and practices

\begin{tabular}{|c|c|c|c|c|c|}
\hline Factor & $\begin{array}{l}\text { Fasting High } \\
\text { (one month or } \\
\text { more per year) } \\
\text { n }(\%)\end{array}$ & $\begin{array}{l}\text { Fasting moderate } \\
\text { (less than } 1 \\
\text { month per year) } \\
n(\%)\end{array}$ & Odds ratio & $95 \% \mathrm{CI}$ & p-value \\
\hline \multicolumn{6}{|l|}{ Circumcision } \\
\hline Circumcised & 504(99) & $52(91)$ & & & \\
\hline Uncircumcised & $7(1)$ & $5(9)$ & 6.92 & $2.09-22.94$ & $<0.001$ \\
\hline \multicolumn{6}{|c|}{ Ever had sex during menstruation } \\
\hline Yes & $100(15)$ & $30(25)$ & & & \\
\hline No & $583(85)$ & $91(75)$ & 1.92 & $1.21-3.06$ & 0.005 \\
\hline \multicolumn{6}{|c|}{ Ever drank alcohol } \\
\hline Yes & $152(15)$ & $50(31)$ & & & \\
\hline No & $861(85)$ & $112(69)$ & 1.26 & $0.66-2.40$ & 0.491 \\
\hline \multicolumn{6}{|l|}{ Ever had sex } \\
\hline Yes & $723(71)$ & $128(78)$ & & & \\
\hline No & $299(29)$ & $36(22)$ & 1.47 & $0.99-2.18$ & 0.054 \\
\hline
\end{tabular}

\section{Behavioral factors associated with high HIV risk perception}

Respondents with high HIV risk perception were more likely to have multiple sexual partners outside marriage (odds ratio 8.86, 95\% CI 1.07-73.07, $\mathrm{p}=0.014)$. They were also more likely to have ever used narcotic drugs for recreation (odds ratio 3.92, 95\% CI 1.74-8.81, $\mathrm{p}<0.001)$.

\section{Behavioral factors associated with parental existence}

Respondents with both parents alive were more likely to report abstaining from sex (odds ratio 2.12 , 95\% CI 1.60-2.77, $\mathrm{p}<0.001)$. They were also more likely to have had one life time marital sexual partner (odds ratio $2.17,95 \%$ CI 1.12-4.19, $\mathrm{p}=0.018)$. In addition they were more likely to have ever been tested for HIV (odds ratio 1.59, 95\% CI 1.25-2.01, $\mathrm{p}<0.001$ ).

\section{Discussion}

The lower prevalence of HIV infection among Muslim respondents compared to Christian respondents is consistent with what was documented in the 2005 Uganda national sero-behavioral survey 1. Muslim respondents with high HIV risk perception who thought they were likely to be infected were indeed more likely to test HIV positive. High HIV risk perception was associated with risky behaviors of sex outside marriage and use of narcotic drugs. This is consistent with observations by other researchers in Uganda ${ }^{12}$.
It was also observed that the existence of parents was associated with lower HIV infection rates. Parental presence was associated with abstaining from sex, having one lifetime marital partner and testing for HIV infection. This is consistent with what others have found that having an intact family may be protective against risky behaviors ${ }^{13,14}$.

The presence of Sujda as an indicator of high religiosity was associated with lower HIV infections. The risk of being HIV positive for those with no Sujda was approximately three times of those with sujda. The most likely mechanism for this is that during regular prayers, which are evidenced by Sujda, individuals remember God and His guidance on regulation of HIV-risk behaviors. This results in constantly reminding the individual to exercise self-control. Consequently, more people with Sujda were abstaining from sex, were being more faithful in marriage and were less likely to drink alcohol and take narcotic drugs. This is consistent with the postulated mechanism of self-control through which religiosity operates to influence favorable outcomes. ${ }^{15}$ Indeed, Islam teaches selfcontrol and one of the techniques for doing this is to engage in regular prayers. ${ }^{4,16}$

The findings of the study support inclusion of religiosity in HIV prevention interventions for Muslim communities. Those who have high religiosity and adhere to their religious teachings such as regular prayers, have lower HIV infection rates. The data also supports the use of the Islamic approach to HIV/AIDS, which is a five pillar combination package that includes use of Islamic teachings in 
addressing HIV prevention. ${ }^{5}$ Some of the Islamic teachings related to Sujda from the Holy Qur'an which may be used in educating and reminding Muslim communities about HIV prevention, include the following:

"Recite what is sent of the Book by inspiration to you and establish regular prayers, for prayers keep one away from shameful and evil deeds, and remembrance of Allah is the greatest thing in life without doubt and Allah knows the deeds that you do." (Holy Qur'an 29:45)

This teaching is supported by data from the study, where those who establish regular prayers and have Sujda are less likely to engage in HIV-risk behaviors and hence less likely to have HIV infections. The findings of the study can therefore be used by Imams and other stakeholders to increase the HIV protective behavior of regular prayers within their target Muslim communities.

Another Islamic teaching from the Holy Qur'an which is supported by the study findings and which may be used by Imams and other stakeholders in HIV prevention is as follows:

"Mubammad is the messenger of Allah; and those who are with him are strong against unbelievers; but compassionate among each other. You will see them bow and prostrate themselves in prayer seeking the Grace from God and His good pleasure. On their faces are their marks being the traces of this prostration. This is the similitude in the Taurat (Torah); and their similitude in the Gospel is: like a seed which sends forth its blade; then makes it strong; it then becomes thick and stands on its own stem filling the sowers with wonder and delight. As a result, it fills the unbelievers with rage at them. Allah has promised those among them who believe and do righteous deeds forgiveness and a great reward." (Holy Qur'an 48:29).

This Islamic teaching can be used by Imams and other stakeholders to show the value of Sujda, the marker of regular prayers on the forehead. One of Allah's rewards for having Sujda is decreasing the risk of getting HIV infection.

Regarding fasting, the supportive teaching from the Holy Quran is as follows:

"O you who believe! Fasting is prescribed for you as it was prescribed to those before you that you may learn self-restraint." (Holy Qur'an 2:183).

According to this teaching, fasting facilitates selfcontrol related to risky behaviors. Promoting fasting is therefore likely to result in lower HIV infections. From the study, those who fasted for one month or more per year were more likely to abstain from sex, avoid drinking alcohol, and avoid sex during menstruation. They were also more likely to be circumcised. Adopting these behaviours was likely to reduce their risk of getting HIV infections. Indeed, male circumcision has been shown to significantly reduce the risk of HIV infections ${ }^{17}$.

On the issue of sex during menstruation there is an Islamic teaching in the Holy Qur'an which discourages this. It is as follows:

"They ask you about menstruation. Tell them: 'This is a discomfort; therefore, keep away from women (do not have sexual intercourse) during their menstrual periods and do not approach them until they are clean again. When they have cleansed themselves, then you may approach them in the manner Allah has enjoined for you. Surely Allah loves those who turn to Him in repentance and loves those who keep themselves clean." (Holy Qur'an 2:222)

This teaching implies that there are dangers in having sex during menstruation. One of these is the increased risk of getting HIV infection noted in the study. Promotion of this teaching in the communities is likely to contribute to reduction of new HIV infections.

With regards to alcohol there is a teaching discouraging use of alcohol which is as follows: "They ask you about drinking alcohol and gambling. Tell them: There is great sin in both although they may have some benefit for men; but their sin is greater than their benefit." (Holy Qur'an 2:219).

This teaching implies there are dangers in drinking alcohol and one of these is the increased risk of getting HIV infections as demonstrated in the study. If this teaching is promoted more within the communities it is likely to contribute to HIV prevention.

Parental responsibility in bringing up children is another important issue that Imams and other stakeholders need to emphasize. It is parents that usually determine the children's religiosity. As shown in the study, if parents are alive and presumably providing guidance to their offspring, the chances of being involved in risky behaviors and getting HIV infection are reduced. The issue of children listening to their parents' guidance also needs to be emphasized. One Islamic teaching from the Holy Qur'an to support this which should be promoted further within the communities is as follows:

"Your Lord has decreed to you that: you shall worship none but Him, and you shall be kind to your parents; If one or both of them live to their old age in your lifetime, you shall not say to them any word of contempt nor repel them and you shall address them in kind words. You shall lower to them your wings of humility out of mercy for them and pray: $O$ my Lord! Bestow on them Your blessings just as they cherished me when I was a little child." (Holy Qur'an 17:23-24). African Health Sciences Vol 12 No 3 September 2012 
Promoting religious teachings and practices such as those described above, is one of the innovative responses for preventing HIV transmission that is being advocated for by other scholars as well. It has been noted that many world religions have teachings that encourage self- control. For example there is the Christian Lenten restriction for 40 days, the Hindu Brahmacharya practices where some young men restrict sexual activity, and the Buddhist general notions of self-restraint which includes life long dietary restrictions ${ }^{18}$. Religious teachings that promote self-control are therefore present in all world religions. Identifying and promoting those teachings likely to constrain risky behaviors that may lead to new HIV infections is probably a worthwhile effort for religious leaders in all world religions in their struggle to combat HIV/AIDS within their communities. The data from the study supports this approach.

Among the limitations of this study is the fact that the required sample size for Muslims in the case-control study was not obtained. The power to identify differences between cases and controls was therefore diminished. Some significant differences in religiosity between cases and controls may not have been detected for this reason. In addition the respondents were generally quite religious people and they could have given socially desirable answers expected of a religious community. This could also reduce the chances of finding significant differences in religiosity between the cases and controls. However, Sujda did not have this limitation because its presence was objectively verified by the interviewers. The limitation of Sujda is that a minority of people who perform regular prayers may not develop Sujda due to the nature of their skin not responding to repeated pressure of prostration. This could result in over estimating the magnitude of the association between regular prayers and HIV infection.

\section{Conclusion}

Sujda, indicative of regular prayers and more frequent fasting, were dimensions of religiosity that were significantly associated with lower HIV infection rates in this study. Imams and other stakeholders should use this information to support and intensify the Islamic Approach to HIV/AIDS prevention within Muslim communities.

\section{Acknowledgements}

We are grateful to the communities in Wakiso district who participated in this study.

We would also like to thank all the staff of Saidina Abubakar Islamic Hospital who participated in data collection, entry and analysis for the study. The support given to us by Makerere University School of Public Health- CDC/HIV/AIDS Fellowship program and the Federation of Islamic Medical Associations (FIMA) is very much appreciated. This work is a contribution to knowledge generation and dissemination which is the core business of the FIMA HIV/AIDS Resource Center housed at SAIH and locally managed by the Islamic Medical Association of Uganda (IMAU).

\section{References}

1. Ministry of Health $(\mathrm{MOH})$ Uganda and ORC Macro 2006. Uganda HIV/AIDS sero behavioral survey 2004-2005. Calverton Maryland US: Ministry of Health ORC Macro.

2. Noon HM, Haneef MA, Yusof SA, Amin RM. Religiosity and social problems in Malaysia. Intellectual Discourse 2003: 11(1):77-87

3. Adam UF. Medicine in the Quran and Sunnah. Islamic Medical Association of Nigeria, UDUTH, Sokoto 2001.

4. Badri M. The AIDS Crisis: A natural product of modernity's sexual revolution. Medeena Books, Kuala Lumpur, Malaysia 2000.

5. Islamic Medical Association of Uganda. Islamic approach to HIV/AIDS. Enhancing the community response: Training guidelines for Imams, community educators, and mosque communities. Available at www.imauuganda.org under downloads

6. Schesselman J. Case-control studies: design, conduct and analysis. New York. Oxford University Press 1982.

7. Uganda Ministry of Health 2005. HIV Counseling and Testing: A National Counselor Training Manual.

8. Fetzer Institute, National Institute on Aging Working Group. Multidimensional Measurement of Religiousness/Spirituality for use in Health research. The John Fetzer Institute, Michigan 2003. Accessed at www.fetzer.org under resources.

9. Yaffee RA. Stata 10 Times Series and forecasting. Journal of Statistical Software, vol. 23. Software Review 1, http:// www.jstatsoft.org/v23/s01/ paper, December 2007. 
10. Norman GR, Streiner DL. Biostatistics the Bare Essentials. $3^{\text {rd }}$ ed. Shelton Connecticut. People's Medical Publishing House, 2008.

11. Rehle T, Saidel T, Mills S, Magnani R. Evaluating programs for HIV/AIDS prevention and care in developing countries. A handbook for program managers and decision makers. Family Health International, USAID 2001.

12. Kengeya-Kayondo J, Carpenter L, Kintu P, Nabaitu J, Pool. R, Whitworth J. Risk perception and HIV prevalence in 15,000 adults in rural Uganda. AIDS 1999: 13(16): 2295-2302.

13. Koenig HG, McCullough ME, Larson DB. Handbook of Religion and Health. Oxford University Press 2001.

14. Merril R, Salazar D, Gardner N. Relationship between family religiosity and drug use behavior among youth. Social behavior and personality 2001; 29: 347-357.
15. McCullough ME, Willoughby B. Religion, selfregulation and self-control: Associations, explanations and implications. Psychological Bulletin 2009; 135 (1): 69-93.

16. Balogun AS. Islamic perspectives on HIV/AIDS and antiretroviral treatment. The case of Nigeria. African Journal of AIDS Research 2010; 9(4): 459466.

17. Gray RH, Kigozi G, Serwadda D. et al. Male circumcision for HIV prevention in men in Rakai, Uganda: a randomized trial. Lancet 2007; 369: 657-666.

18. Parkhurst J, Whiteside A. Innovative responses for preventing HIV transmission: The protective value of population-wide interruptions of risky activity. Southern African Journal of HIV Medicine 2010; 11(1):19-21. 